\title{
SPECTRUM OF FINDINGS IN PULMONARY INFECTIONS ON CT / HRCT SCAN OF THE CHEST
}

Shailesh G. Sangani ${ }^{1}$, B. Suprabhat S², Seema V. Grover ${ }^{3}$, Abhijeet A. Wagh', Krupa A. Dave5, Suhas Anantkawalas 6

\section{HOW TO CITE THIS ARTICLE:}

Shailesh G. Sangani, B. Suprabhat S, Seema V. Grover, Abhijeet A. Wagh, Krupa A. Dave, Suhas Anantkawalas. "Spectrum of Findings in Pulmonary Infections on CT / HRCT Scan of the Chest". Journal of Evolution of Medical and Dental Sciences 2014; Vol. 3, Issue 45, September 18; Page: 10972-10985,

DOI: $10.14260 /$ jemds/2014/3432

ABSTRACT: OBJECTIVE: The purpose of this study is to describe the spectrum of findings that can be seen on CT scan in pulmonary infections. MATERIALS AND METHODS: A retrospective analysis of 100 patients with pulmonary infections who had undergone CT/HRCT scans of the chest in our Department or Radiology at Terna Sahyadri Speciality Hospital \& Research Centre affiliated to Terna Medical College in Navi Mumbai was done to analyze the various findings. The CT findings were grouped and tabulated to assess the predominance of various findings on CT scan. RESULTS: Out of the 100 patients analysed, consolidation and lymph nodal involvement were the dominant findings. There were overlap of findings in some of the patients. Lymph nodal involvement was noted in all the cases with majority having mediastinal nodal involvement rather than hilar, which is not seen clearly on a plain X-ray chest. The other CT findings were nodules, pleural fluid, post infective sequalae, ground glassing, bronchiectasis and cavities. CONCLUSIONS: The role of imaging in pulmonary infection is to determine the presence of, localization of, and extent of infection, to detect predisposing factors, to detect complications and in follow up of the infection. Radiological signs on plain X-ray of chest are often not very typical and have a limited role in predicting the cause and infecting organisms. Computed tomography(CT) scan with post contrast study whenever required and high resolution computed tomography(HRCT) are the best available modalities to assess the lung parenchyma, interstitium, mediastinum and pleura.

KEYWORDS: Computed tomography, high resolution computed tomography, pulmonary infection.

INTRODUCTION: Despite advances in diagnosis and treatment, pulmonary infections are a major cause of mortality and morbidity in adult patients. The spectrum of organism known to cause respiratory infections is broad. It is constantly increasing as new pathogens are identified and as the host immune response is incapacitated due to medications or other diseases and immune responses.

The clinician evaluating the patient with a known or suspected pulmonary infection faces the diagnostic challenge because of clinical overlap of signs and symptoms and variable radiological manifestations. The number of immunocompromised patients has dramatically increased because of AIDS epidemic, advances in cancer chemotherapy and expanding organ transplantation.(1)

CT, more so HRCT study of the chest, has become a frontline investigation for evaluation of such patients. In essence HRCT seeks to maximize spatial resolution and thereby approach a morphological/pathological representation of the disease process. ${ }^{(2)}$

MATERIALS AND METHODS: A retrospective analysis of 100 cases of pulmonary infections that had undergone CT/HRCT scan in department of radiology at Terna Sahyadri Specialty Hospital and 
Research centre, Navi Mumbai was done to know the predominant findings, variety of lesions and appearances.

Majority of the cases underwent plain / HRCT study of the chest with intravenous contrast enhanced studies performed in a few of the patients.

The study included patients of all age groups and both male and female patients. The scans were performed on a Siemens Somatom Sensation 64 multidetector CT scan machine. Nonionic intravenous contrast was used for the contrast enhanced studies. Images were mainly documented using lung and mediastinal windows. HRCT sections were displayed using $1 \mathrm{~mm}$ slice thickness at periodic intervals and the HRCT sections were obtained in deep inspiration as far as possible.

Retrograde analysis of 100 patients was considered as collected data and grouped as per their CT findings in a variety of subgroups as consolidation, ground glassing, nodules, bronchiectasis, cavities, pleural fluid / effusion / collection, lymph nodes and post infective sequalae. Data obtained is given in the master table below.

$\underline{T A B L E}$ depicting the spectrum of chest lesion and their overlapping percentage wise occurrences in 100 patients.

\begin{tabular}{|c|c|c|c|c|c|c|c|c|c|c|}
\hline \multicolumn{2}{|c|}{ Sex } & $\begin{array}{l}\text { Age groups } \\
\text { in years }\end{array}$ & Consolidation & $\begin{array}{l}\text { Ground } \\
\text { glassing }\end{array}$ & Nodules & Bronchiectasis & Pleural fluid & Cavities & $\begin{array}{l}\text { Post infective } \\
\text { sequelae }\end{array}$ & $\begin{array}{l}\text { Lymph } \\
\text { nodes }\end{array}$ \\
\hline $\mathbf{M}$ & $\mathbf{F}$ & $1-10=0$ & $\begin{array}{c}\mathbf{8 8} \\
(\mathbf{8 8 \%}) \\
\end{array}$ & 24 & $\begin{array}{c}48 \\
(48 \%) \\
\end{array}$ & $\begin{array}{c}24 \\
(24 \%) \\
\end{array}$ & $\begin{array}{c}34 \\
(34 \%) \\
\end{array}$ & $\begin{array}{c}16 \\
(16 \%) \\
\end{array}$ & $\begin{array}{c}28 \\
(28 \%) \\
\end{array}$ & $\begin{array}{l}100 \\
(100 \%)\end{array}$ \\
\hline 58 & 42 & $11-20=6$ & Lobar-22(25\%) & & $\begin{array}{l}\text { Airspace- } \\
10(20.8 \%)\end{array}$ & $\begin{array}{l}\text { Traction- } \\
12(50 \%)\end{array}$ & Right-16(47\%) & $\begin{array}{c}\text { Multiple- } \\
8(50 \%)\end{array}$ & $\begin{array}{l}\text { Scarring- } \\
22(78.5 \%)\end{array}$ & $\begin{array}{l}\text { Mediastinal- } \\
80(80 \%)\end{array}$ \\
\hline & & $21-30=10$ & Segmental-8(9\%) & & $\begin{array}{c}\text { Nodular } \\
\text { consolidation- } \\
8(16.4 \%)\end{array}$ & & $\begin{array}{c}\text { Left- } \\
14(41.2 \%)\end{array}$ & $\begin{array}{c}\text { Single cavity- } \\
\mathbf{4 ( 2 5 \% )}\end{array}$ & $\begin{array}{l}\text { Fibrocalcific- } \\
6(21.5 \%)\end{array}$ & $\begin{array}{l}\text { Hilar }-20 \text { of } \\
100(20 \%)- \\
\text { right } 14 \text {, left } \\
6\end{array}$ \\
\hline & & $31-40=22$ & $\begin{array}{c}\text { Patchy- } \\
\text { 12(13.6\%) }\end{array}$ & & Calcified-6(8\%) & & $\begin{array}{c}\text { Both sided- } \\
\text { 4(11\%) }\end{array}$ & $\begin{array}{c}\text { Heterogenous } \\
\text { densities } \\
\text { within- } \\
2(12.5 \%)\end{array}$ & & $\begin{array}{l}\text { Necrotic - 8 } \\
\text { of } 100(8 \%)\end{array}$ \\
\hline & & $41-50=18$ & $\begin{array}{l}\text { Multifocal- } \\
\text { 24(27.2\%) }\end{array}$ & & Miliary-4(8.3\%) & & $\begin{array}{c}\text { Simple } \\
\text { effusion- } \\
\mathbf{3 0}(\mathbf{8 8 . 2 \%})\end{array}$ & $\begin{array}{l}\text { Crescent } \\
\text { sign- } \\
2(12.5 \%)\end{array}$ & & $\begin{array}{l}\text { Calcific - 20 } \\
\text { of } 100(20 \%)\end{array}$ \\
\hline & & $51-60=10$ & $\begin{array}{c}\text { Air } \\
\text { bronchograms- } \\
12(13.6 \%)\end{array}$ & & $\begin{array}{c}\text { Centrilobular- } \\
2(4.1 \%)\end{array}$ & & $\begin{array}{c}\text { Empyema- } \\
\text { 2(5.9\%) }\end{array}$ & & & \\
\hline & & $61-70=16$ & $\begin{array}{c}\text { Cavitationor } \\
\text { breakdown- } \\
10(11.4 \%)\end{array}$ & & & & $\begin{array}{c}\text { Loculated- } \\
2(5.9 \%)\end{array}$ & & & \\
\hline & & $71-80=16$ & & & & & & & & \\
\hline & & $81-90=2$ & & & & & & & & \\
\hline & & $91-100=0$ & & & & & & & & \\
\hline
\end{tabular}

RESULTS: The case study of the 100 patients showed dominance of adult patients between the age groups of 31-40 years (22\%) with mild male preponderance(58\%). Though a spectrum of findings can be seen on CT in pulmonary infections, consolidation and lymph nodal involvement were the predominant findings in the case study. There was overlap of findings in some patients.

88 (88\%) patients had consolidation, of which 22 (25\%) had lobar consolidation, 8(9\%) had segmental, 12(13.6\%) had patchy and 24(27.2\%) patients had multifocal consolidation. Air bronchograms were seen in $12(13.6 \%)$ patients and areas of cavitation / breakdown were noted in $10(11.4 \%)$ patients.

Lymph nodal involvement was noted in all the 100 cases with $80(80 \%)$ patients having mediastinal nodal involvement and 20(20\%) patients having hilar nodal involvement. (14 cases on 
the right and 6 cases on the left). Calcification was seen in $20(20 \%)$ patients and necrotic areas were noted in $8(8 \%)$ patients.

$48(48 \%)$ patients had nodules, of which $10(20.8 \%)$ were air space nodules, $8(16.4 \%)$ were in the form of nodular consolidation, $6(8 \%)$ showed calcification, $4(8.3 \%)$ were military and $2(4.1 \%)$ were centrilobular.

Pleural fluid was noted in 34(34\%) patients, 16(47\%) had right sided pleural fluid, $14(41.2 \%)$ had left sided fluid and $4(11 \%)$ had fluid bilaterally. Pleural effusion was simple effusion in $30(88.2 \%)$ cases, showed features of empyema in $2(5.9 \%)$ cases and was loculated in $2(5.9 \%)$ cases.

Ground glassing was observed in $24(24 \%)$ patients while bronchiectatic changes were evident in another $24(24 \%)$ cases with 12 patients showing traction bronchiectasis. There were cavities in $16(16 \%)$ of which $8(50 \%)$ cases had multiple cavities and $4(25 \%)$ had single cavity, $2(12.5 \%)$ had heterogenous densities within and another $2(12.5 \%)$ cases demonstrated the meniscus sign.

DISCUSSION: CT findings can be varied in pulmonary infections. There could be overlap of findings or a spectrum of findings in cases of pulmonary infections. The commonly encountered findings in this case study were consolidation, ground glassing, nodules, bronchiectasis, cavities, pleural effusion/fluid/collection, lymph nodes and post infective sequalae.

CONSOLIDATION: The term consolidation means increased lung attenuation with obscuration of pulmonary vessels.(2) By definition diseases that produce consolidation are characterized by replacement of alveolar air by another substance such as blood, pus, edema or cells. ${ }^{(2)}$ Consolidation may be lobar as in klebsiella, pneumonia,(1) segmental, patchy/ nonsegmental or multifocal. Bronchopneumonia typically shows patchy pattern(1) or a homogenous segmental consolidation.(1) Gram negative, anaerobic bacteria and occasionally streptococcus pneumonia are responsible for breakdown and abscess formation with subsequent cavitation.(3) An air bronchogram is usually associated with lobar pneumonia and suggests air in bronchi against a background of consolidation.(4) Typical appearance of community acquired pneumonia is one of a single subpleural area of alveolar consolidation with blurred margins restricted to the area next to the fissures progressing to a systemized segmental opacity affecting one or several contiguous segments or a lobe with or without the air bronchogram sign. Bilateral involvement that predominantly affects the lung bases with abscess formation is suggestive pseudomonas aeruginosa infection (5). An enlarged lobe with bulging fissures connected to voluminous oedema is a classical presentation of klebsiella pneumoniae infection. ${ }^{(5)}$

Non segmental consolidation represents consolidation distributed in several segments of the lung (more than two). It can be seen due to infectious diseases including lobar pneumonia caused by streptococcus, klebsiella or legionella. Other infections include mycoplasma pneumonia, tuberculosis, measles etc. Air bronchograms are frequently found in non segmental consolidation and are rarely seen with segmental consolidation.(6) An air bronchogram is usually reassuring of a non obstructive etiology, but can be seen also in cases of bronchoalveolar carcinoma and lymphoma.

Common CT findings in pneumonia caused by streptococcus are non segmental consolidation, reticular opacities and centrilobular nodules.(6) Klebsiella pneumonitis is seen as ground glass 
opacities followed by consolidation and intralobular reticular opacity and legionella pneumonia begins as a segmental bronchopneumonia and has the ability to convert to anon segmental distribution or lobar pneumonia in two to three weeks.(6)

Our 88 cases of pneumonias $22(25 \%)$ had lobar pneumonia, 27.2\% had multifocal pneumonias, $13.6 \%$ had patchy pneumonias, 12 patients $(13.6 \%)$ had air bronchogram and 10 had cavitation or breakdown (11.4\%). Out of 88 patients, $9 \%$ had segmental pneumonia. (Figures - 1, 2)

GROUND GLASS OPACITY: Ground glass opacity is defined as hazy increase in lung attenuation that is not obscuring the underlying vessels.(2) It could be alveolar, interstitial or alveolo-interstitial in location. Ground glass opacity is a highly significant finding as it often indicates the presence of an ongoing active and potentially treatable process. It is commonly seen in immunocompromised patients with pneumocystis pneumonia. $(2,7)$ When associated with thickening of the interlobular septa it is called crazy paving and can be seen in pneumocystis jiroveci pneumonia.(7) In patients with acute symptoms as in infections, association of ground glassing with active disease is very high.

Non neoplastic ground glass opacity (GGO) is caused by partial airspace filling, interstitial thickening with inflammation, edema, fibrosis, partial collapse of alveoli or focal hemorrhage. GGO can be classified as pre GGO and halo or mixed GGO types according to the presence or absence of solid components. Halo sign corresponds to GGO surrounding the circumference of a nodule or mass. Pure GGO can be seen in acute inflammation and halo or mixed GGO pattern is commonly seen in cases with hemorrhagic nodules such as invasive aspergillosis(8). Extensive GGO is the principal finding in pneumocystis jiroveci pneumonia reflecting accumulation of intra-alveolar fibrin, debris and organisms. ${ }^{(9)}$

In immunocompetent patients respiratory syncitial virus or varicella infection should be considered when ground glass opacities predominate (5). In immunocompromised patients infection with pneumocystis jiroveci, cytomegalovirus pneumonia or mycoplasma pneumonia may be assessed on CT as GGO sparing the cortex and predominantly affecting the upper region.(5) In patients with immune deficiency not caused by AIDS, GGO's are common but non specific as they can be caused by viral or pyogenic infections.(5) In our study, ground glass opacity was present in 24 out of 100 patients (24\%). (Figures 3, 4)

NODULES: A pulmonary nodule may be broadly defined as any relatively sharply defined, discrete, nearly circular opacity within the lung ranging in size from 2-30 mm.(2) Micronodules are referred to nodules less than 3-7 mm. Miliary nodules are usually innumerable, measuring1-3 mms in size scattered throughout the lungs.(4) They can be seen in pulmonary tuberculosis- Nodules may be centrilobular, perilymphatic or random in location and can be of ground glass or soft tissue attenuation. A tree in bud appearance consists of linear branching opacities connected to centrilobular nodules of soft tissue attenuation that has more than one branching site. This sign corresponds with bronchial dilatation filled with mucus, pus or fluid.(2) These can be seen in tuberculosis, bacterial infections and allergic bronchopulmonary aspergillosis (ABPA). $(7,10)$

In viral infection and those caused by mycoplasma pneumonia the most common findings are reticular or reticulonodular opacities with blurred margins that may have a nodular or diffuse pattern predominantly in the perihilar region(5). Pulmonary nodules caused by infection, possibly with cavitation are most often seen in nosocomial pneumonias in immunocompetent patients.(5) If 
nodules have a peripheral ground glass halo it usually points to a perinodular hemorrhage. In patients with neutropenia this sign though inconsistent is highly suggestive of invasive aspergillosis where it is associated with subpleural consolidation. ${ }^{(5,8)}$

Intrapulmonary lymph node, tuberculoma, histoplasmoma, focal organizing pneumonia and lung abscess can manifest as solid nodules. Tuberculomas commonly appear as smooth maginated round nodules on CT with calcification, cavitation and satellite nodules sometimes seen. They show variable enhancement, usually rim enhancing granulomatous tissue in the periphery and central low attenuation caseation necrosis.(8) Tuberculomas sometimes show spiculated margins especially in a background of fibrotic or emphysematous parenchyma where they appear as cancerous lesions. ${ }^{(8)}$

Centrilobular nodules and areas of tree in bud appearance have been described in tuberculosis, non tuberculous mycobacterial infection and aspergillosis.(11) Detection of associated cavitatory lesions suggests the diagnosis of mycobacterium tuberculosis, other mycobacterial or fungal infections.(11) In reactivation of tuberculosis the areas of tree in bud appearance have increased density and distinct margins.(5) They are readily found with cavitation predominantly flocalised to the superior segments of inferior lobes and apicoposterior segment of superior lobes.(5) Aspergillosis and / or bronchiolitis must be considered in immunocompromised patients.(5)

Bacteria most often involved in bronchopneumonia are staphyloccus aureus, hemophilus influenza, pseudomonas aeruginosa, anerobes and some species of fungus, especially aspergillosis. Thickening of bronchial walls, centrilobular nodules and areas of tree in bud appearance are the expression of infectious bronchiolitis.(5) associated with bronchiectasis, particularly with involvement of the middle lobe and lingual suggest the diagnosis of atypical mycobacterial infection.(11) Small nodules and areas of tree in bud appearance are uncommon in patients with AIDS and pneumocystis jiroveci pneumonia and usually indicate the presence of infectious bronchioloitis from other organisms. (9)

Granulomatous inflammation occurs in approximately 5\% of patients, usually early in the course of HIV infection when the immunodeficiency is more limited and can become evident on HRCT as a solitary nodule/mass or multiple nodules ranging from few mms to more than a centimeter. ${ }^{(\mathrm{H})}$ Randomly distributed micronodules fitting with a hematogenous pattern could suggest tuberculosis, histoplasmosis, candidiasis, blastomycosis or a viral cause especially in immunocompromised patients. (5)

Although tree in bud sign was initially assumed to be pathognomic of mycobacterial tuberculosis, it is now recognized as a common pattern that can be seen in other infections. In mycobacterium tuberculosis, tree in bud appearance results from impaction of caseous material in bronchioles of secondary pulmonary lobule.(12) Tree in bud appearance may also be seen on other types of pneumonia as pus / inflammatory secretions impact the distal airways. In our study, 48 out of 100 patients (48\%) had nodules out of which 10 patients $(20.8 \%)$ had airspace nodules and nodular consolidation was seen in 8 out $48(16.6 \%)$ patients. Six patients out of $48(8 \%)$ had calcified nodules. Only 4 out of 48 (8.3\%) had miliary nodules and 2 out of 48 (4.1\%) had centrilobular nodules. (Figures 5, 6)

BRONCHIECTASIS: Bronchiectasis is generally defined as irreversible bronchial dilatation(2) often with thickening of the bronchial wall. It could be irreversible localized or diffuse dilatation resulting from chronic infection, proximal airway obstruction or congenital abnormality.(2) Bronchial dilatation 
is the most specific sign and is present when the broncho-arterial ratio exceeds one.(2) The dilatation is seen as signet ring sign on cross section. $(2,7,13)$ Other signs of bronchiectasis include lack of bronchial tapering, visualization of peripheral airways, mucoid impaction. $(4,13)$ In order of increasing severity, bronchiectasis has been classified into cylindrical, varicose and cystic varieties.(13)

A finger in glove sign also called as inverted V or Y, cluster of grapes sign is formed by mucoid impaction within the dilated bronchial tree. Mucoid impacted dilated bronchial tree is commonly seen in allergic bronchopulmonary aspergiillosis with central bronchiectasis also noted in this condition. $(3,10,13)$ Bronchiectasis with or without mucoid impaction can also be seen in tuberculosis and other bacterial infections. ${ }^{(7)}$ Traction bronchiectasis is seen in areas of scarring or fibrosis where there is traction on the walls of the bronchi by fibrous tissue.

Bronchiectasis can be focal or diffuse. In contrast to diffuse bronchiectasis, focal bronchiectasis requires diagnostic bronchoscopy in almost all patients. Extrinsic compression most commonly caused by lymphadenopathy usually from previous granulomatous exposure is an acquired cause of focal bronchiectasis.(13)

Bronchiectasis not caused by cystic fibrosis remains an important cause of suppurative lung disease in the developing world.(14) Eastham et al(14) in their study of 93 paediatric patients with non cystic fibrosis bronchiectasis found that the most common association was a previous pneumonic illness. Hemophilus influenza and streptococcus pneumonia were most commonly isolated different from bacterial pattern seen in established bronchiectasis in adults where pseudomonas aeruginosa is a major pathogen.

Post infectious bronchiectasis is a frequent cause of lower lung predominant bronchiectasis. It is less seen today because of better control of tuberculosis, earlier treatment of pneumonia and immunization. However recurrent infections still remain a frequent cause of bronchiectasis in immune suppressed patients. Non tuberculous mycobacterial infection such as Mycobacterium avium intracellulare is the most common acquired cause of bronchiectasis predominantly involving the right middle lobe and lingual.(13) It is typically seen in women over 60 years, presents with chronic infection, bronchiectasis, mucoid impaction and bronchioloitis.

Bronchiectasis with bronchial wall thickening, areas of tree in bud appearance, consolidation, cavitation and / or necrotic lymphadenopathy as well as an appropriate exposure history supports the diagnosis of mycobacterial tuberculosis.(12) In contradistinction to non tuberculous mycobacterial pneumonia in which bronchiectasis, centrilobular nodules or tree in bud appearance and volume loss predominate ${ }^{(12)}$. In our study 24 out of 100 (24\%) had bronchiectasis out of which 12 patients (50\%) had traction bronchiectasis. (Figure 7, 8).

Cavity: A cavity is a lucency exceeding one $\mathrm{cm}$ in diameter and surrounded by a complete wall which is a $3 \mathrm{~mm}$ or more in thickness.(2) According to Ryu et al(15) a cavity is referred to an air containing lesion with a relatively thick wall (more than $4 \mathrm{mms}$ ) or within an area of a surrounding infiltrate or mass. Differential diagnosis of cavitatory lesion is broader and includes neoplasms, many types of infectious processes and abscesses (bacterial, mycobacteria, fungi, parasites), pulmonary infarct, septic embolism, vasculitides, congenital anomalies and progressive massive fibrosis occurring with pneumoconiosis. More often than not, cavitation implies an active process.

HRCT is particularly helpful in detection of small foci of cavitation in areas of dense nodularity and scarring. Tuberculous cavity develops in a consolidated segment as the caseation 
necrosis erodes into the bronchial tree expelling the liquid debris. On HRCT cavities due to tuberculosis can be thick or thin walled and may have smooth or irregular margins.(16) Most isolated cavitatory lesions are of neoplastic origin, however in patients with AIDS it is usually caused by infections including bacteria (including nocardia), mycobacteria, pneumocystis carinii, other fungi and cytomegalovirus. ${ }^{(15)}$

Thick walled cavities in tuberculosis probably represent early stages of necrotizing consolidation and may resolve completely, leave a scar, become thin walled or remain open at the end of treatment.(16) Presence of multiple cavities (more than three) in an area of consolidation is found more frequently in pulmonary tuberculosis than in any other lesions. Cavitation in consolidated lung is also seen in necrotizing pneumonias most commonly caused by staphylococcal aureus, gram negative bacteria, anerobes. $(5,15)$

Cavitation seen with bacterial pneumonia, particularly anerobic bacteria, can evolve into a discrete abscess, a relatively round cavity with an irregular thick wall that may be associated with an air fluid level.(5,15) CT may also show single or multiple masses between 2 and $6 \mathrm{cms}$ in diameter with central hypoattenuation or cavitation representing purulent liquefying necrosis and peripheral enhancement on contrast enhanced CT(5)

Cavitation is also the hallmark of post primary tuberculosis that has a predilection for upper lung with smooth or irregular inner wall.(15) Non tuberculous mycobacterial infection in lung can also be associated with cavitation. Endemic fungal infections can also cause cavitating lesions, more commonly with chronic than acute disease.(15) Cavitatory lesions are also seen in opportunistic fungal infections. A crescent sign suggests intracavitatory contents with a thin crescent of residual air $(3,4)$ Crescent sign is commonly seen in fungal infections as in an aspergilloma(3)

Lung abscess is often preceeded by aspiration. Aspiration commonly occurs in patients with alcoholism, immune supression, poor dental hygiene and mental retardation. In our study of 100 patients, we found cavities in 16 of those patients (16\%). Out of these 16 cases of cavities, 8 had multiple cavities (50\%) and 4 had single cavities (25\%). Heterogenous densities were seen in 2 out of 16 cavities $(12.5 \%)$ and crescent sign was seen in 2 out of the 16 cases $(12.5 \%)$, (Figures 9,10$)$.

Lymph nodes: Hilar and mediastinal lymphnodes are commonly seen in all most all patients with active tuberculosis and in HIV positive patients.(7) Mediastinal lymphadenopathy is more commonly seen in HIV positive patients as compared to seronegative patients. Hilar lymphadenopathy in ABPA is probably due to reactive hyperplasia of lymphoid tissue.(10) Involved lymph nodes may show a typical rim enhancing pattern suggestive of central necrosis in tuberculosis. $(4,5)$

Lymph nodal calcification could be seen as a natural course of the disease or secondary to treatment. Lymph nodal enlargement / involvement secondary to infection normally do not encase vessels. They may however cause airway compression with post obstructive changes distally. Extrinsic compression most commonly caused by lymphadenopathy usually from previous granulomatous exposure is an acquired cause of focal bronchiectasis.(13) Adronikou et al(17) in their study of 100 children with clinically suspected pulmonary tuberculosis found that approximately one fourth of the 100 children may have bronchial compression in childhood.

Adronikou et al(17) also found that lymphadenopathy was common in their study of 100 children with clinically suspected pulmonary tuberculosis. It was greater than a centimeter in 46 cases. Subcarinal region was the most frequently involved and also the site of largest lymph node 
masses. They also found a typical ghost like enhancement rather than discrete enhancement with low density centres.

In our study, lymph node enlargement was seen in all the patients (100\%). Out of these 80 had predominantly mediastinal lymph node enlargement (80\%) and 20 had predominantly hilar enlargement (20\%). There was considerable overlap in both groups; subcarinal and precarinal group was involved in almost 50 cases of all. Calcification was seen in 20 of 100 lymph nodes (20\%) and necrosis within lymph nodes was seen in 8 of 100 cases (8\%). (Figures 11 to 13).

Pleural effusion / fluid/ collection: Pleural effusion is accumulation of pleural fluid in pleural space and can accumulate whenever the rate of fluid formation exceeds the rate of fluid removal. Generally, collections of pleural fluid are recognized on CT scan of thorax as arcuate areas of homogenous density paralleling the chest wall. Exudative pleural fluid is due to increased capillary permeability and is usually seen in infections.

Pleural effusion is seen in $20-60 \%$ cases of acute bacterial pneumonias.(5) It is a common complication in tuberculosis where it is mostly exudative and commonly unilateral.(7) Pleural fluid can accumulate in patients with pneumonia even when the pleural space is uninfected. This syn /parapneumonic effusion occurs due to increase in the visceral pleura permeability. Over 90\% of parapneumonic effusion without pleural thickening resolve when treated appropriately. Empyema describes a purulent pleural effusion resulting from infection of the pleural space. Contrast enhanced sections reveal the split pleura sign in such cases.

Study conducted by Abramowitz et al(18) revealed that CT attenuation values did not show any potential clinical value in characterization of pleural fluid. Additional pleural CT appearance features such as loculation, pleural thickening and nodules are not reliable in differentiating exudates from tansudates, although their prevalence is higher among exudative effusion.

Arenaa et al(19) evaluated contrast enhanced CT of 211 patients with pleural effusion of definitive diagnosis. They evaluated images for presence and extent of effusion, pleural thickening or nodules, extrapulmonary fat and other changes in the mediastinum or lung. Comparison between benign and malignant effusion, transudates and exudates and between empyemas and other paarapneumonic effusions were carried out. Loculation, pleural thickening, nodules and increased extrapulmonary fat density were only present in exudative effusions. Multiple pleural nodules and nodular pleural thickening were the only pleural findings limited to malignant effusion. The signs were also seen in empyemas than in other parapneumonic effusions. Although differences between CT findings of empyema and other parapneumonic effusion exist, there is no finding that can absolutely differentiate between them.

In our study we found pleural fluid in 34 out of 100 cases (34\%). Out of these 34 cases of pleural effusion, 16 had right sided involvement (47\%), 14 had left sided collection (41.1\%), and 4 of $34(11.7 \%)$ had both sided collections. Out of total 34 cases, 30 cases had simple pleural effusion (88.2\%), 2 had loculated collection and 2 had empyema, i.e $5.9 \%$ each. (Figure 14)

Post infective sequalae: These represent tell tale evidence of any previous infection and usually represent an inactive stage. These could be in the form of volume loss, parenchymal scarring, fibronodular or fibrocalcific densities and compensatory hyperinflation. Fibrocavitatory lesions on the other side merit clinicopathological correlation to exclude activity. In our study we found $28 \%$ 
cases with post infective sequalae. Scarring was seen in 22 out of 28 cases (78.5)and 6 had fibrocalcific lesions (21.5\%), (Figure 15).

CONCLUSIONS: There could be a variety of findings with overlap on CT scan in pulmonary infections. Lymph node enlargement and consolidation were the dominant presentations of pulmonary infections in our case study. CT/HRCT studies gave us more insight into the disease process. When correlated with the clinical, pathological / hematological reports, the findings help us to narrow the differential diagnosis. These findings are also useful in diagnosing the variety and severity of pulmonary infections. They help in further management and treatment of potentially curable chest diseases like infections and also in preventing further complications.

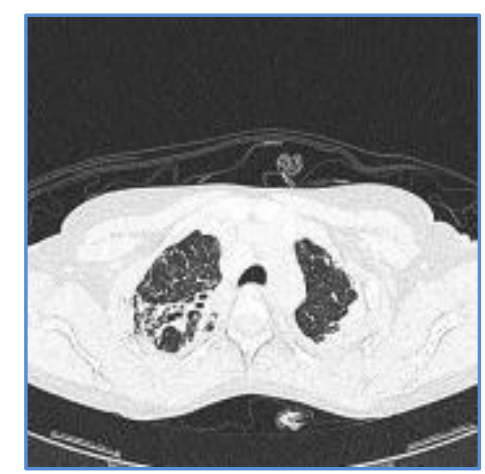

\section{Fig. 1: Consolidation in right} upper lobe with air

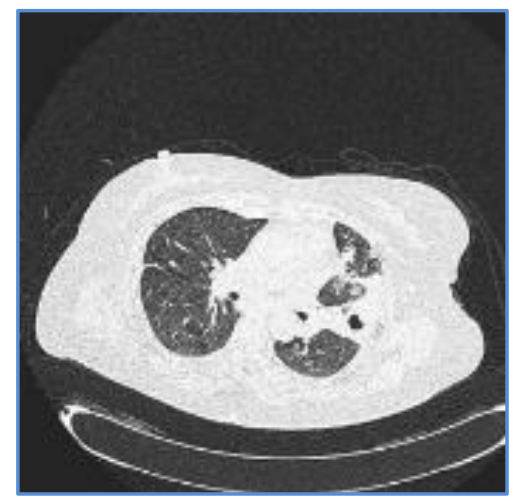

Fig. 3: Consolidation with cavitation in left upper lobe

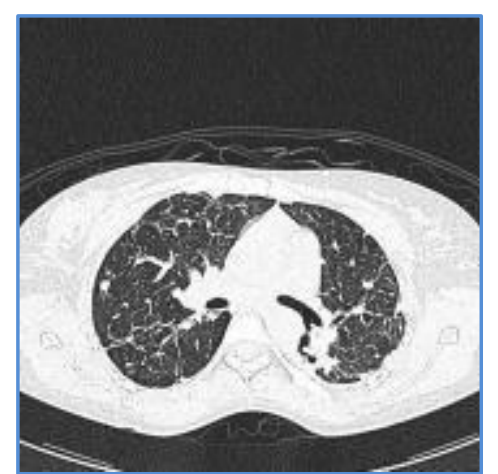

Fig. 2: Consolidation in left peri-para Hilar lung region

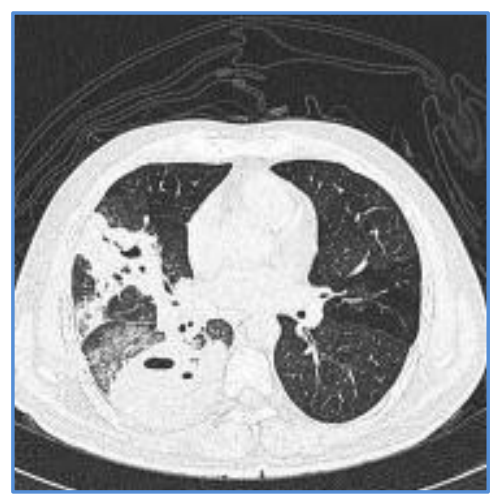

Fig. 4: Multifocal consolidation with cavitation $\&$ air bronchogram in right lung 


\section{ORIGINAL ARTICLE}

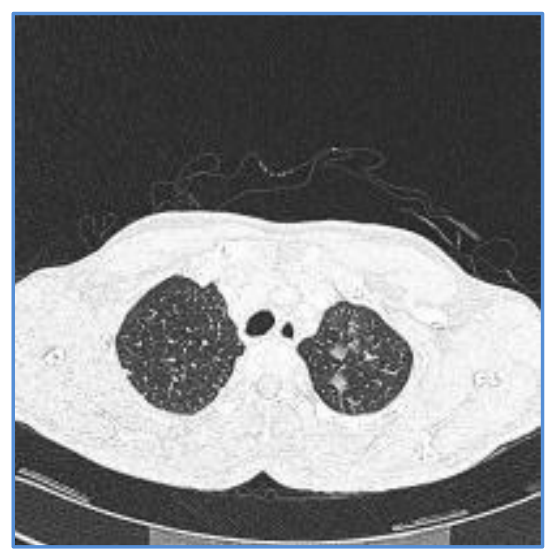

Fig. 5: Ground glass opacities in left upper lobe

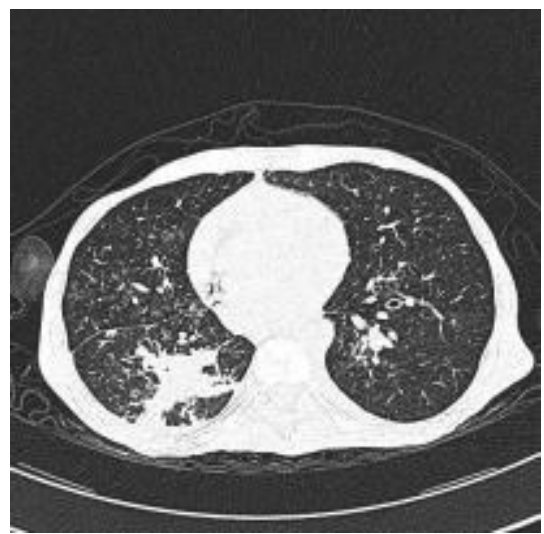

Fig. 7: Nodular areas, ground glass opacities and patchy consolidation in Right middle

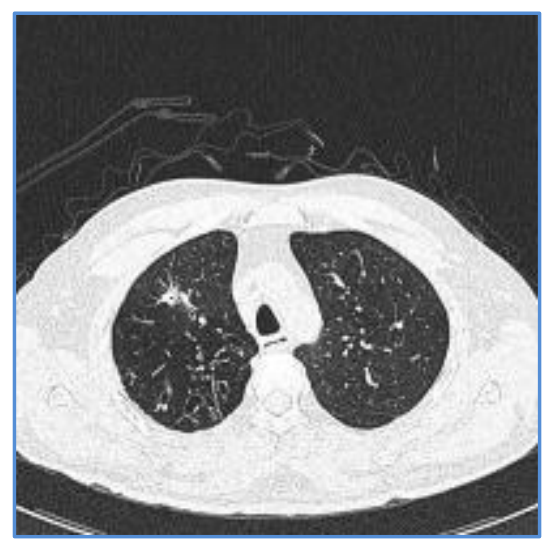

Fig. 9: Bronchiectasis in right upper lobe

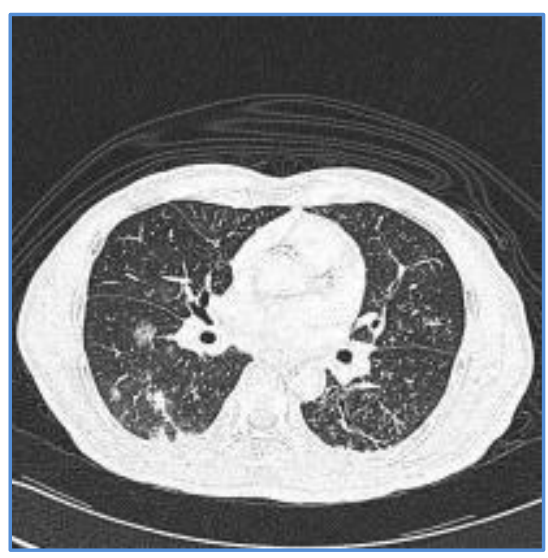

Fig. 6: Ground glass opacities in right lower lobe

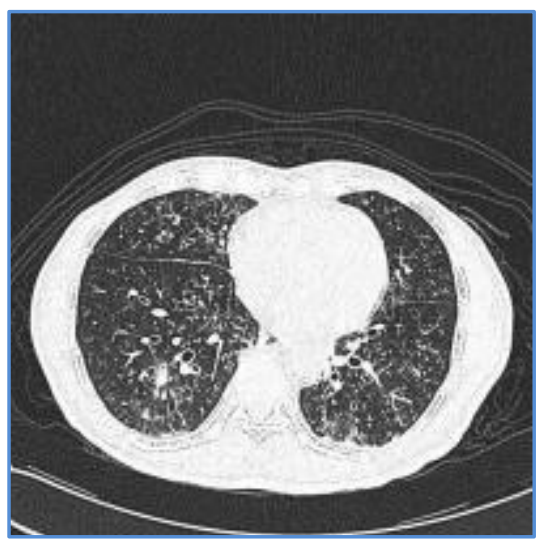

Fig. 8: Tree in Bud appearances in left lower lobe

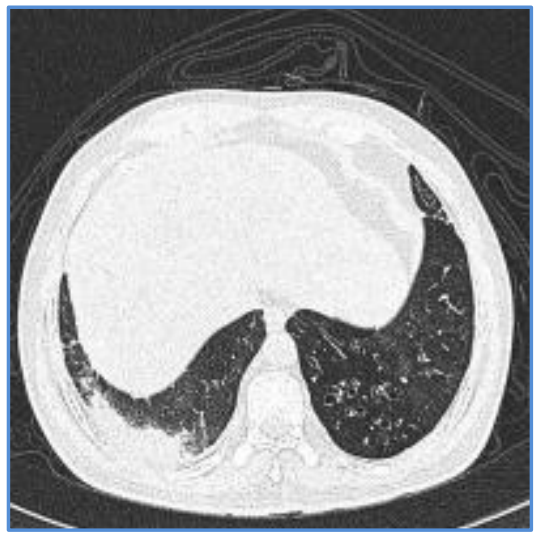

Fig. 10: Signet ring sign s/o bronchiectasis in left lower lobe 


\section{ORIGINAL ARTICLE}

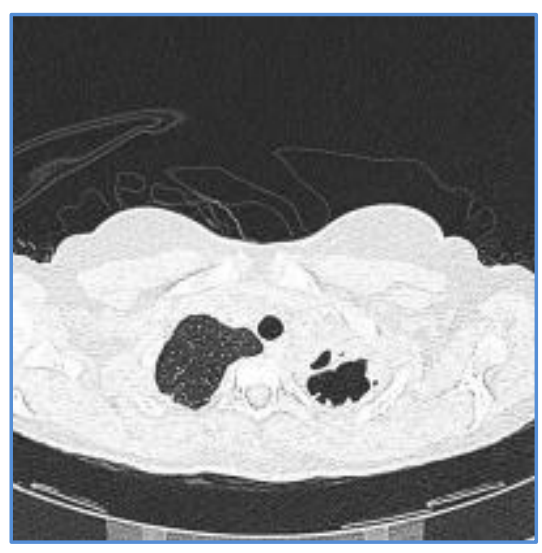

Fig. 11: Left upper lobe cavitations with irregular inner wall in larger cavity

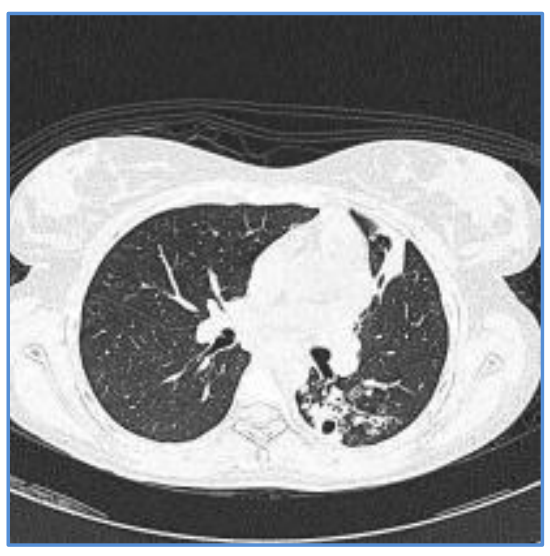

Fig. 12: Left lower lobe consolidation with eccentric are of cavitation

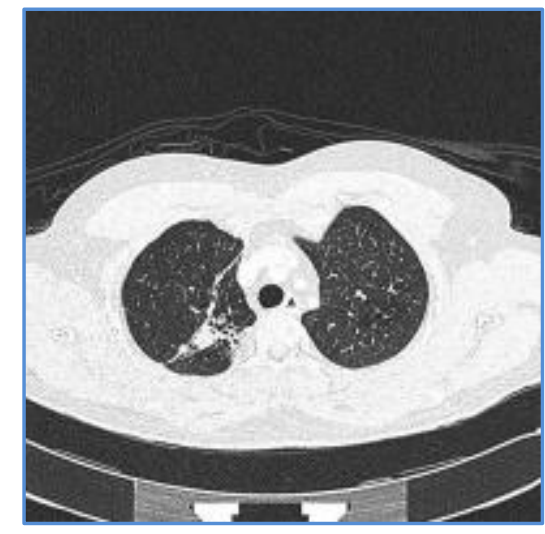

Fig. 13: Right upper lobe cavity with contents giving Meniscus sign s/o fungal ball

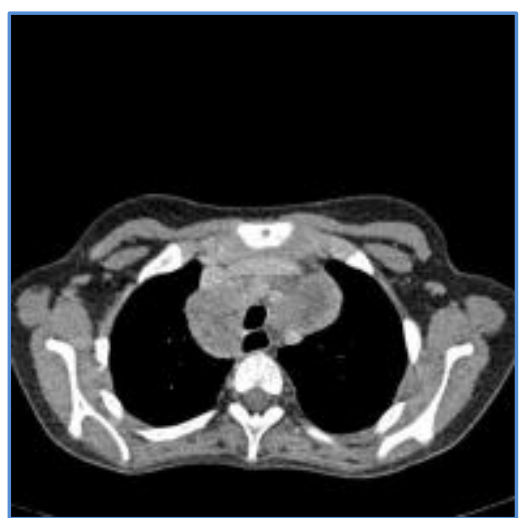

Fig. 14: Non calcific pretracheal, right paratracheal and perivascular lymphadenopathy

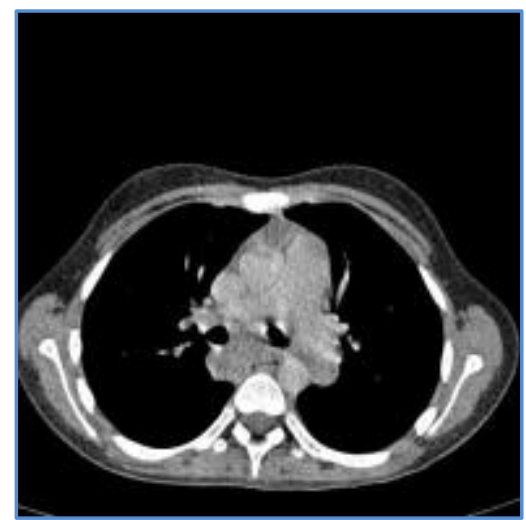

Fig. 15: Azygoesophageal lymphadenopathy causing esophageal compression 


\section{ORIGINAL ARTICLE}

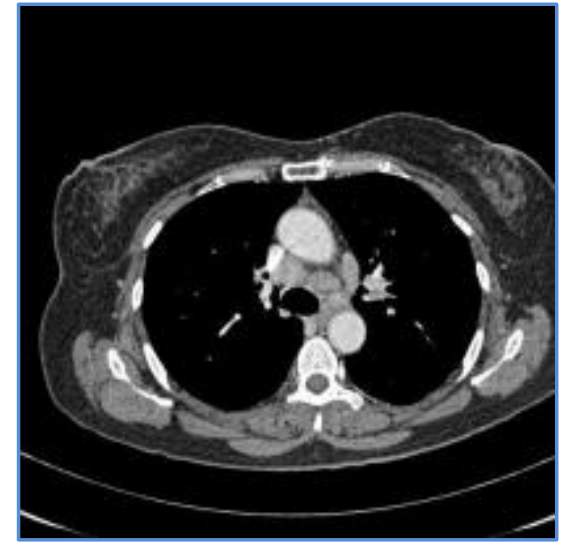

Fig. 16: Discrete enhancing pretracheal and aortopulmonic lymph nodes

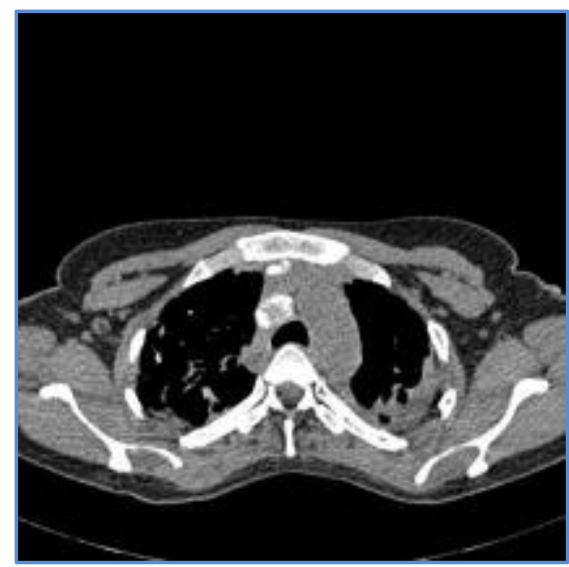

Fig. 18: Calcified pretracheal lymph nodes

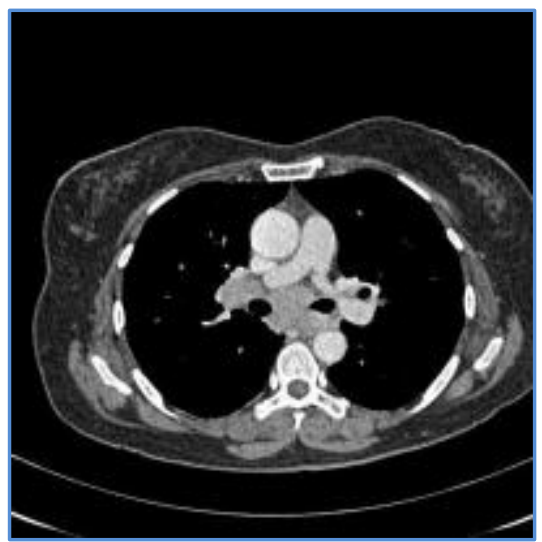

Fig. 17: Enhancing right Hilar \& subcarinal lymph nodes

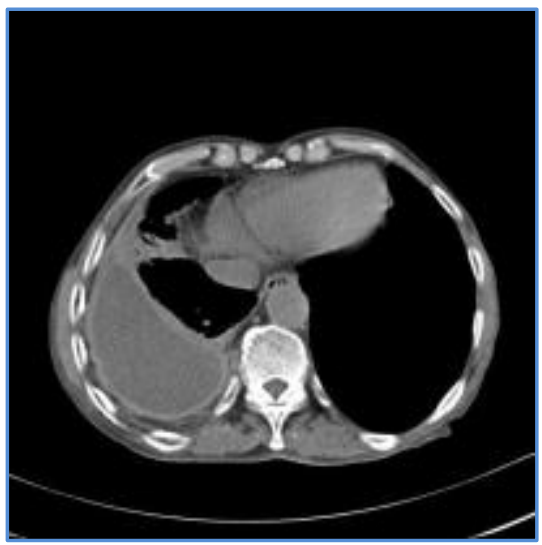

Fig. 19: Right pleural fluid with thickened layer

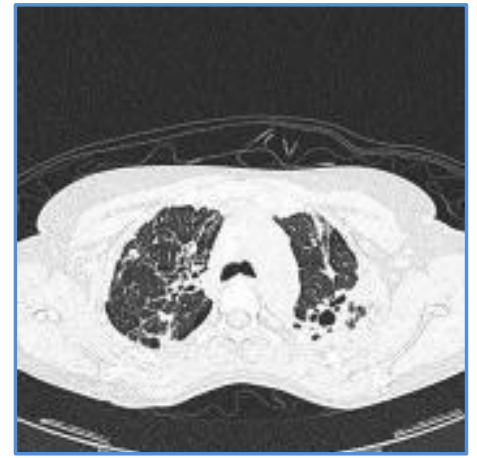

Fig. 20: Bilateral Fibronodualr scarring in upper lobes 


\section{BIBLIOGRAPHY:}

1. T Franquet. Imaging of pneumonia: Trends and algorithms. European Respiratory journal. 2001July1; 8(1): 196-208.

2. Michael. B. Gotway, Gautham P. Reddy, W. Richard Webb, Brett M. Elicker, Jessica W. T. Leung. High resolution computed tomography of the lung: patterns of disease and differential diagnoses. RCNA. 2005; 43: 513-542.

3. Kemal Odev, Huseyin Ozbiner. Imaging findings of focal multiple cystic and cavitatory lung lesions. European journal of general medicine. 2012; 9(11): 3-14.

4. Van Meighem I. M, W. F. Dewever, J. A. Verschakelen. Lung infection in radiology: A summary of frequently depicted signs. JBR-BTR. 2005; 88: 66-71.

5. C. Beigelman-Aubry, C. Godet, E. Caumes. Lung infections: The radiologist's perspective. Diagnostic and interventional imaging. 2012June; 93(6): 431-440.

6. Attiya Haroon, Futoshi Higa, Shusaku Haranaga, Satomi Yara, Masao Tateyama, Haaley. L Cash, Takashi Ogura, Jiro Fujita. Differential diagnosis of non-segmental consolidation. J. Pulmon Resp Med. 2013; S8: 001.

7. Swapnadeep Singh Atwal, Swapnil Puranik, Ramavathu Kumar Venu Madhav, Abhinetri KSV, B. B. Sharma, Umesh Chand Garga. HRCT lung spectrum in symptomatic adult HIV positive patients in south east asian nation. Journal of clinical and diagnostic research. 2014; Jun 8(6): RC12-RC16.

8. Kiyoma Furuya, Kataro Yasumori, Sadanori Takeo, Iku Sakino, Norika Uesugi, Selya Momosaki, Toru Muranaka. Lung CT: Part 1, Mimickers of Lung Cancer-Spectrum of CT findings with pathologic correlation. American Journal of Roentgenology. 2012: 199: W454W463.

9. Jeffrey P. Kanne, Ronald R. Yandow, Cristopher A. Meyer. Pneumocystis jiroveci pneumonia: High resolution CT findings in patients with and without HIV infection. American jornal of Roentgenology. 2012; 199: W555-W561.

10. Agarwal R, Khan A, M Aggarwal AN, Gupta D. Pictorial essay- Allergic Bronchopulmonary Aspergillosis. IJRI 2011; 21: 242-52.

11. Gerald F. Abbott, Melissa L, Rosado-de-Christenson, Santiago E. R. Rossi, Saul Suster. Imaging of small airways disease. Journal of Thoracic Imaging. 2009; 24: 285-298.

12. Verma Nupur, Chung, Jonathan H, Mohammed, Tan Lucien. Tree in bud sign. Journal of thoracic imaging. 2012March; 27(2): pw27.

13. Lucy Contin, Alexander A Bankier, Ronald L. Eisenberg. Bronchiectasis. AJR. 2009; 193: W158-W171.

14. K. M. Eastham, A J Fall, L. Mikhe, D A Spencer. The need to redefine non cystic fibrosis bronchiectasis in childhood. Thorax2004; 59: 324-327.

15. Jay. H. Ryu, Stephen J. Swensen. Cystic and cavitatory lung diseases: Focal and Diffuse. Mayo Clinic Proc. 2003; 78: 744-752.

16. Chandrajeet Yadav, Aman Gupta, Amit Tiwari, Prashant Muasale. Role of imaging in management of pulmonary tuberculosis. Journal of evolution of medical and dental sciences. 2013 May. 
17. Andronikou s, Joseph E, Lucas S, Brachmeyer S, Du Toit G, Zar H, Swingler G. CT scanning for the detection of tuberculous mediastinal and hilar lymphadenopathy in children. Pediatric Radiology. 2004Mar; 34(3): 232-6.

18. Yigal Abramowitz, Natalia Simananovsky, Michael. S Goldstein, Nurith Hiller. Pleural effusion: characterization with CT attenuation values and CT appearance. AJR. 2009; 192: 618-623.

19. Arenas-Jimenez, Alonso Charterina, Sauchez Paya J, Fernandez Latorre, Gil Sanchez, Lloret Llorens. Evaluation of CT findings for diagnosis of pleural effusion. Eur Radiol. 2000; 10(4): 681-90.

\section{AUTHORS:}

1. Shailesh G. Sangani

2. B. Suprabhat $S$.

3. Seema V. Grover

4. Abhijeet A. Wagh

5. Krupa A. Dave

6. Suhas Anantkawalas

\section{PARTICULARS OF CONTRIBUTORS:}

1. Professor \& HOD, Department of Radiology, Terna Sahyadri Hospital \& Research Centre, Terna Medical College, Navi Mumbai.

2. Lecturer, Department of Radiology, Terna Sahyadri Hospital \& Research Centre, Terna Medical College, Navi Mumbai.

3. Lecturer, Department of Radiology, Terna Sahyadri Hospital \& Research Centre, Terna Medical College, Navi Mumbai.

4. Senior Resident, Department of Radiology, Terna Sahyadri Hospital \& Research Centre, Terna Medical College, Navi Mumbai.
5. Senior Resident, Department of Radiology, Terna Sahyadri Hospital \& Research Centre, Terna Medical College, Navi Mumbai.

6. Junior Resident, Department of Radiology, Terna Sahyadri Hospital \& Research Centre, Terna Medical College, Navi Mumbai.

\section{NAME ADDRESS EMAIL ID OF THE CORRESPONDING AUTHOR:}

Dr. Shailesh G. Sangani,

Professor \& Head, Department of Radiology,

Terna Sahyadri Hospital \& Research Centre, Plot 12, Sector 22, Nerul (West), Navi Mumbai-400706, Maharasthra, India.

Email: dr.sgsangani@yahoo.co.in

Date of Submission: 27/08/2014. Date of Peer Review: 28/08/2014. Date of Acceptance: 09/09/2014. Date of Publishing: 16/09/2014. 